\title{
Down's syndrome: prevalence and ionising radiation in an area of north west England 1957-91
}

\author{
John P Bound, Brian J Francis, Peter W Harvey
}

\begin{abstract}
Objective - To analyse the prevalence of Down's syndrome in a specific, geographical area and seek to explain variations with particular reference to ionising radiation.

Design - Cases were ascertained by one paediatrician as part of a prospective survey of major congenital malformations in children born to residents of an area of Lancashire between 1957 and 1991. Temporal changes in prevalence rates were detected by a grid search technique using Poisson log linear models. These models were also used to determine the association between prevalence and ionising radiation from atomic fall out.
\end{abstract}

Setting - The Fylde district of Lancashire in the north west of England.

Patients - There were 167 cases, including five stillbirths and eight terminations, among 124015 total births in a population which increased from about 250000 to over 300000 during the study period.

Main results - There was significant increase in the prevalence of all cases conceived in 1963 and 1964, and a lesser peak in 1958 which did not quite reach statistical significance. There was no evidence that the increased prevalence in 1963-64 was a result of changes in the maternal age distribution in the population. Babies of mothers aged 35 years and over accounted for more of the variation, especially in 1958 when their increase was significant. There was a highly significant association between prevalence and radiation from fallout produced by atmospheric testing of atomic weapons. The 1963-64 peak coincided with the maximum estimated radiation dose. The lesser peak in 1958 also coincided with increased exposure to radiation from fallout, possibly enhanced by ground deposits after a fire at the Windscale reactor in October 1957.

Conclusion - This study provides further support for low dose ionising radiation as one aetiological factor in Down's syndrome.

(f Epidemiol Community Health 1995;49:164-170)

Department of

Lancaster Infirmary,

Lancaster

P W Harvey

Correspondence to Dr J P Bound

Accepted for publication June 1994
This paper analyses the prevalence at birth of Down's syndrome in the Fylde district of Lancashire over a 35 year period (1957-91) and seeks to explain any significant variations. Down's syndrome results from the presence of an extra chromosome 21 . Over $95 \%$ of cases result from non-disjunction during meiosis. In about $80 \%$ it occurs in the ovum, the risk increasing with maternal age. Ionising radiation is one toxic agent that may lead to a change in the number of chromosomes, ${ }^{1}$ raising the possibility that it plays a part in the aetiology of 21-trisomy. Natural radiation was the sole source to which the population was exposed when Down's syndrome was first described in 1866. Now man-made sources need to be considered as well. The important ones are medical practices, fall out from the atmospheric testing of nuclear weapons, and discharges from nuclear installations (Sellafield is approximately $70 \mathrm{~km}$ north, north west of Blackpool which is in the centre of the Fylde coast).

Natural background radiation is fairly constant in dose at a given place of residence. ${ }^{1}$ In some localities, radon seeping from underlying rocks and accumulating in poorly ventilated houses makes a considerable contribution to the total background dose, but a negligible one to ovarian doses. The main sources of natural background radiation which could be relevant to Down's syndrome are external, from cosmic rays and terrestial gamma rays, and internal from absorbed radioactive materials from the diet. A three year study in Japan found no significant relation between low dose background radiation rate and the incidence of Down's syndrome. ${ }^{2}$ However, the average recorded incidence was lower than in most data, several prefectures showed no cases, and no information on maternal age was available.

Several investigations have attempted to assess the role of maternal medical radiation in Down's syndrome. Two prospective surveys of mothers who had received abdominal radiation ${ }^{34}$ gave conflicting results, but the numbers of Down's syndrome cases involved were very small. A study of a large number of cases 5 led to the conclusion that maternal radiation played some part in the aetiology of Down's syndrome, particularly in mothers of the older age groups. It seemed that the size and frequency of the dose mattered less than the accumulated total of radiation received. One criticism of this study is the reliance on parental memory of radiological examinations, especially as these may have taken place many years previously. ${ }^{6}$ More evidence is needed to clarify the role of low dose radiation in the aetiology of 21-trisomy. 


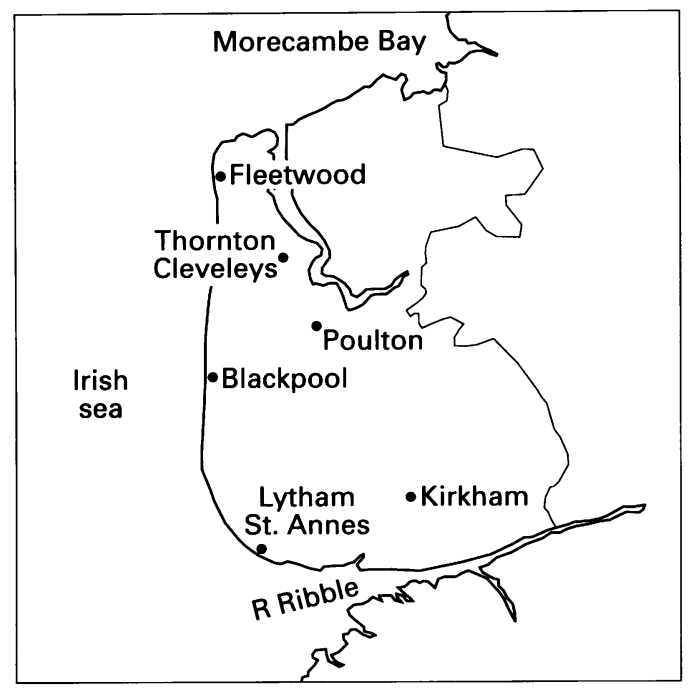

Figure 1 The Fylde of Lancashire.

\section{Methods}

Cases were ascertained as part of a prospective survey, described in detail previously, ${ }^{7}$ of babies with major congenital malformations born in the Fylde (fig 1 ) to residents there during 195781. Recording of babies with Down's syndrome was continued until the end of 1991. The population increased from about 250000 to over 300000 during the 35 years.

The consultant obstetric unit and the children's department of Blackpool Victoria Hospital served all the Fylde and thus ascertainment of cases was facilitated. Data were recorded and checked by one paediatrician as patients were seen at one or more of the following places:

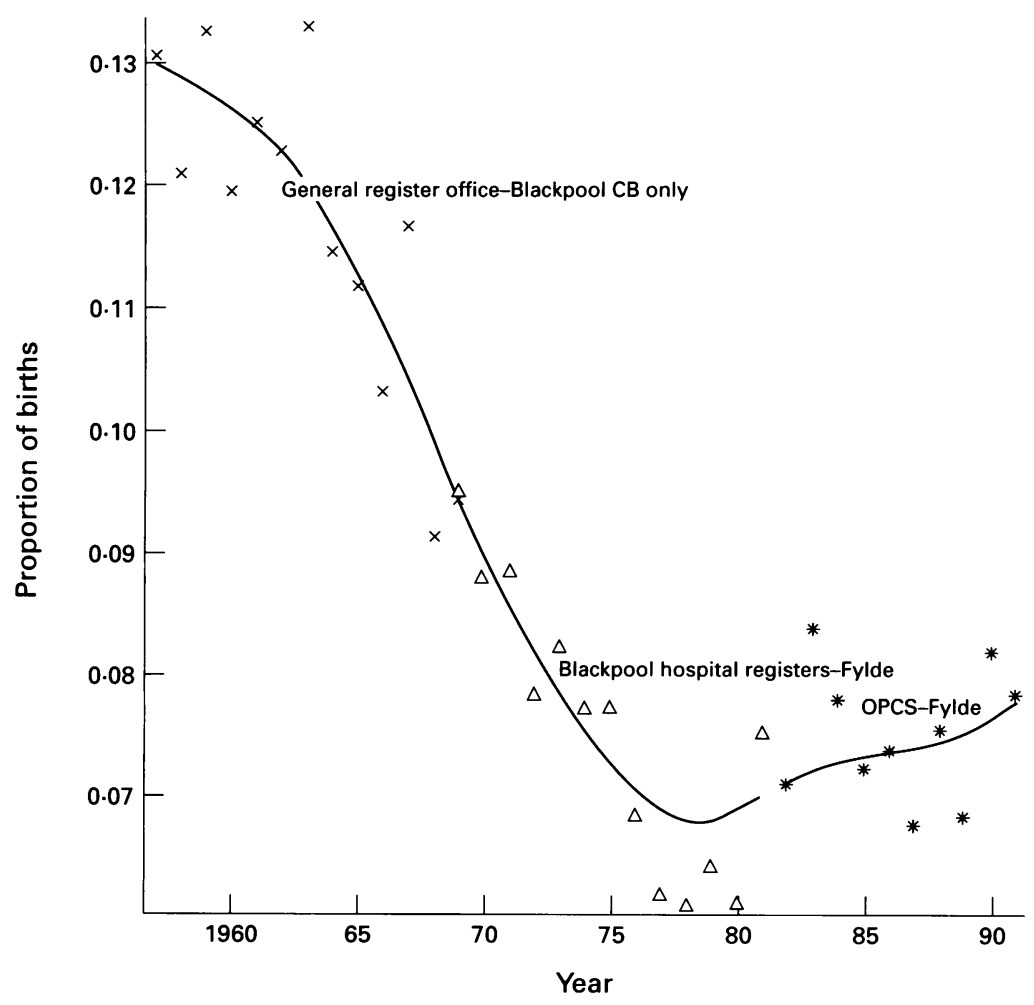

Figure 2 Smoothed proportion of total births to mothers aged 35 years and over in the Fylde.
(1) The special care baby unit and postnatal wards of the maternity hospital;

(2) The general practitioner maternity units which were visited at least weekly. These three units were closed successively, the last one in 1979;

(3) The paediatric clinic in Victoria Hospital and those held in the general practitioner hospitals in the north and south of the Fylde;

(4) The childrens' wards in Victoria Hospital;

(5) Domiciliary visits;

(6) The special schools;

(7) After 1974 in the child development centre to which most Down's syndrome babies were referred.

A very high rate of necropsies was maintained throughout the survey. Confirmation of diagnosis by chromosone analysis began in 1966 .

Terminations of pregnancy for antenatal diagnosis of Down's syndrome were ascertained from the local obstetricians' records. Amniocentesis was offered to mothers of 38 years and over from 1978 and the first termination was carried out in 1982. The age limit was lowered to 37 years in 1985 .

In summary, it was very unlikely that any baby with Down's syndrome was not recorded. There were 167 cases, including five stillbirths and eight terminations, in 124015 total births, giving a rate of 1.35 per 1000 total births. Three cases showed a translocation. One set of twins of the same sex both with Down's syndrome was treated as a single case for this analysis.

The total number of births in the Fylde was obtained annually from the medical officers of health until 1973 and then from the Office of Population Censuses and Surveys. The number of births to mothers aged 35 years and over was available only from 1982 to 1991 , and this is an important age group within which the prevalence of Down's syndrome increases with age. However, the proportion of births to mothers aged 35 years and over resident in Blackpool County Borough was available from 1957 to 1969 . Blackpool residents then accounted for $50 \%$ of Fylde births. From 1969 to 1981, maternal age data were obtained from the consultant hospital registers. Mothers were admitted from all parts of the Fylde and in 1969 made up $44 \%$ of the total births in the area, increasing to $93 \%$ in 1981 . The proportion of births to mothers aged 40 years and over resident in Blackpool County Borough became available only for 1963 and subsequent years.

Calculation of the month of the last menstrual period (LMP) from the date of birth may lead to errors because of varying gestations and can affect the results with small numbers. ${ }^{7}$ The date of the maternal LMP was therefore noted explicitly for each case.

Data on the effective dose equivalents to adults from atomic weapons fallout up to 1985 was obtained from a report of the National Radiological Protection Board, ${ }^{8}$ and figures for the testis up to 1979 came from an additional source. ${ }^{9}$ Doses to the ovary are similar to those for the testis. 
STATISTICAL METHODS

The analysis of the data followed a number of steps. Firstly, the monthly prevalence rates of Down's syndrome were examined. An estimate of the total number of births to mothers in the Fylde for the under 35 and 35 and over groups was then obtained. Separate monthly prevalence rates in the two age groups could then be examined. Finally, an investigation of any potential association with ionising radiation was carried out.

The observed cases were classified by year and by LMP, giving a table of 408 counts from January 1957 to December 1990. A small number of cases had LMP dates in 1956, and these were omitted from the analysis. A previous study 7 had found little seasonal variation in births to Fylde residents, so estimation of the total number of conceptions corresponding to each LMP month was made by calculating the daily birth rate nine months later and multiplying by the number of days in the LMP month.

Estimation of the proportion of all births in the Fylde to women 35 years and over was made by examination of data from the three sources described earlier. Figure 2 shows the three series. We considered it unrealistic to assume that these proportions form one continuous series; for example, the proportion of mothers over 35 might be different in Blackpool County Borough compared to the whole of the Fylde. We therefore attempted to model the data, by assuming that the expected proportion of births born to women over 35 in the Fylde was a smooth unknown function of time. The source of the data is modelled by a shift in this function up or down. The observed proportions are therefore being modelled by a special case of a generalised additive model $^{10}$ or semiparametric generalised linear model ${ }^{11}$ with binomial probability distribution, logit link and with the predictor being a smooth function of time, with an additional factor representing the source of the data. If $\mathrm{p}_{i t}$ is the expected proportion of births to women 35 years or over in year $t$ in series $i$, the model is:

$$
\log \frac{\mathrm{p}_{i t}}{1-\mathrm{p}_{i t}}=\text { SOURCE }_{i}+f(t)
$$

where $f(t)$ is an unknown function to be es-

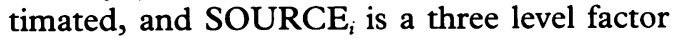
representing the source of the data. The model was fitted in GLIM $^{12}$ using a cubic spline smoother and 5 degrees of freedom (df) for the unknown function $f$; Stasinopoulos and Francis ${ }^{13}$ give details of the GLIM macros needed. The deviance including SOURCE was 33.33 on $28 \mathrm{df}$; excluding SOURCE gave a deviance of 35.30 on $30 \mathrm{df}$. The effect of SOURCE was therefore small (1.97 on $2 \mathrm{df}$ ) which indicated that the source of the data can be safely omitted from the model. Other aspects of the data support this statement. In 1969, the Blackpool County Borough and the hospital register series overlap, and the proportions of births to mothers 35 and over are very close (Blackpool County Borough 0.094; hospital registers 0.095 ). Additionally, in 1981, hospital births formed $93 \%$ of all births in the Fylde, so that the OPCS and the hospital register numbers were similar in the later part of the hospital series. We therefore considered it justified to consider the three sources as contributing to the same continuous series. The smooth estimated function $f$ is also shown in figure 2 .

Techniques for the detection of temporal clustering in epidemiological count data have been proposed. ${ }^{14}{ }^{15}$ These tests assume, however, that under the null hypothesis the underlying counts are equiprobable, which is not the case with our data, as major changes occur in the population number of births over time. Other recent work has concentrated on spacetime clustering. The Ederer-Myers-Mantel procedure $^{16}$ and the Scan statistic ${ }^{17}$ have been proposed but both require a fixed period of time (for example 365 days) to be defined as the temporal unit of interest; clusters of smaller or longer duration may be missed. Other tests such as the Knox test ${ }^{18}$ are global tests for space-time clustering. Although these tests can be adapted to allow for time-varying populations by the collection of control data matched in time, these methods are not appropriate where the primary interest is in the detection of temporal clustering in a region. ${ }^{19}$

We therefore adopted the following log linear modelling procedure. We assume that the observed counts for each distinct month $\mathrm{Y}_{i} i=1$, ..., 408 are Poisson distributed with mean $\mu_{i}$, with the mean depending on the number of births and on any temporal change through the log linear model

$$
\begin{gathered}
\log \left(\mu_{i}\right)=\log \left(\text { BIRTHS }_{i}\right)+\alpha_{1} i=1, \ldots, j-1, j+k, \\
j+k+1, \ldots, 408 \\
\log \left(\mu_{i}\right)=\log \left(\text { BIRTHS }_{i}\right)+\alpha_{2} \quad i=j, \quad j+1, \quad \ldots, \\
j+k-1
\end{gathered}
$$

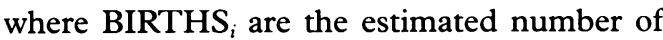
births corresponding to each month of LMP, and $\alpha_{1}$ and $\alpha_{2}$ with $\alpha_{2}>\alpha_{1}$ are logs of two distinct rates $R_{1}$ and $R_{2}$. This model is thus a two rate model and assumes two underlying prevalence rates, a base rate $R_{1}$, which is assumed to be constant for the study period apart from a period of time starting from month $j$ and lasting for $k$ months, when an alternative higher rate $R_{2}$ is assumed. As we were primarily interested in short and medium term variation, we applied an additional restriction that $k$, the length in months of the higher rate period, should be not greater than 36 months.

The parameters $\alpha_{1}, \alpha_{2}, j$ and $k$ were estimated from the data using GLIM. For each combination of $j$ and $k$, maximum likelihood estimates of $\alpha_{1}$ and $\alpha_{2}$ were obtained by using the Poisson error distribution and a declared offset of $\log$ (BIRTHS) and a factor to represent the temporal position of the higher rate. The maximum likelihood estimates of $j$ and $k$ were then those values which maximised the likelihood over the grid of possible values of $j$ and $k$. A single rate model was also fitted, omitting the temporal factor. Alternative solutions can also be found which give local maxima of the likelihood function and these are also considered in the Results section.

A formal likelihood ratio test based on the 


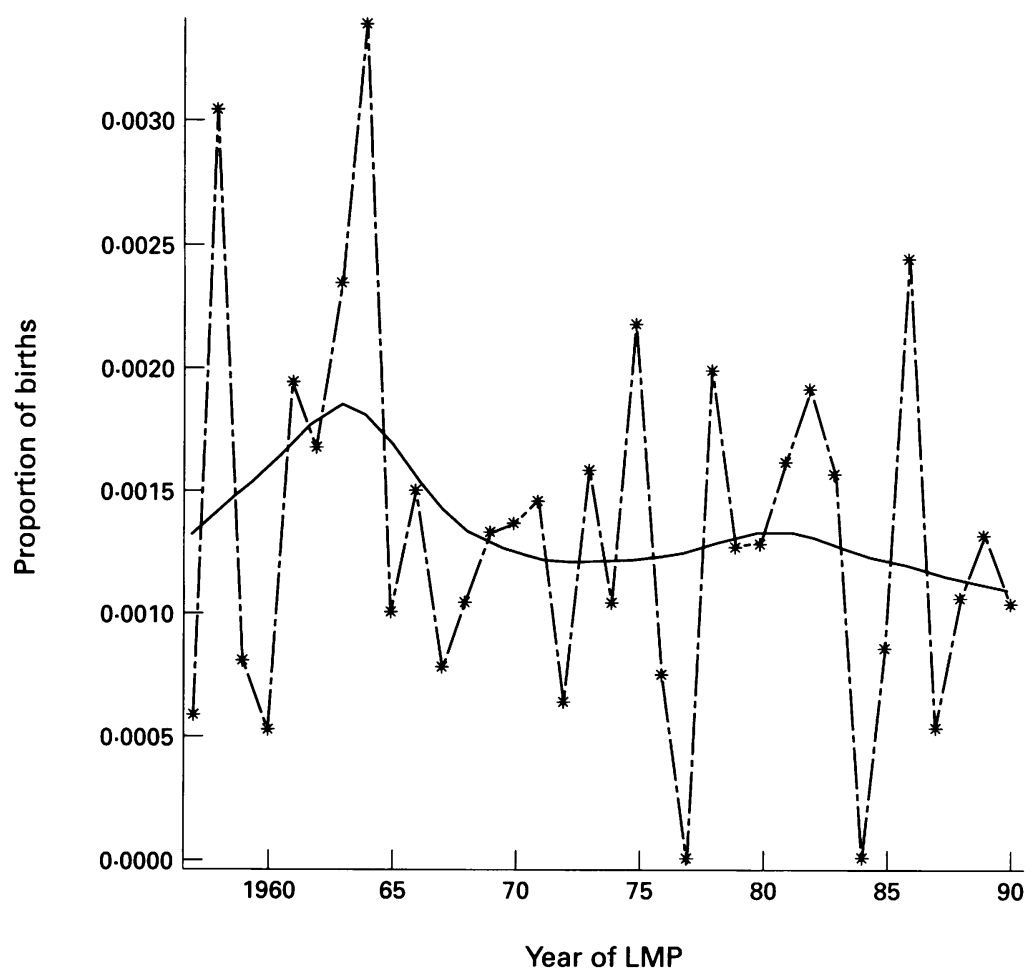

Figure 3 Prevalence of Down's syndrome cases per year. LMP=last menstrual period.

$\chi^{2}$ distribution cannot be used to assess the need for two rates rather than a single rate, as the more restrictive hypothesis is on the boundary of the parameter space and regularity conditions fail. A simultation study was therefore carried out, where for each of 99 simulations the single rate model was assumed to be correct, the two rate model was fitted, and the deviance difference (minus twice the log likelihood ratio) between the two rate model and the single rate model was calculated. The rank of the observed test statistic in the ordered simulated values divided by 100 gives the significance level of the deviance difference. We repeated the above technique separately for the 35 and over and under 35 age groups; the simulation studies gave similar distributions.

Analysis of the prevalence rates for the two age groups together is a simple extension of the above technique. The counts $Y_{i a}$ with the means $\mu_{i a}$ are now classified by month $i$ and age group $a(a=1,2)$, giving 816 distinct counts (408 for each age group). We now assume that the mean $\mu_{i a}$ depends on the number of births, the age group and on any temporal change through the log linear model

$$
\begin{aligned}
& \log \left(\mu_{i a}\right)=\log \left(\text { BIRTHS }_{i a}\right)+\text { AGEGP }_{a}+\alpha_{1} \quad i=1, \\
& \ldots j-1, j+k, j+k+1, \ldots 816 \\
& \log \left(\mu_{i a}\right)=\log \left(\text { BIRTHS }_{i a}\right)+\text { AGEGP }_{a}+\alpha_{2} \quad i=j \text {, } \\
& j+1, \ldots, j+k-1
\end{aligned}
$$

The data have been disaggregated by age group, so we refer to this model as the disaggregated analysis of the total data. The model assumes four underlying prevalence rates, two base rates $R_{1}$ and $R_{3}$, for the under 35 and the 35 and over age groups respectively, which are assumed to be constant for the study period apart from a peak period of time starting from month $j$ and lasting for $k$ months, when alternative higher rates of $R_{2}$ and $R_{4}$ are assumed. We therefore imposed the constraint that $R_{2}>R_{1}$ and $R_{4}>R_{3}$. Simulation was again used to assess significance.

These models can be criticised for failing to take account of possible long term changes in the prevalence of Down's syndrome, and also for not accounting for any temporal dependence in the data. The first was dealt with by including a linear trend in each of the models; this would represent a constant decline or increase over time additional to the effect of any short term peak. The second was dealt with by including an autoregressive term in the form of a lagged count or lagged log count in the model. ${ }^{20}$

Finally, the effect of ionising radiation (measured either by the estimated total dose equivalent or by estimated dose to the testis) was assessed by including it as an explanatory variable in the log linear models;

$\log \left(\mu_{i}\right)=\log \left(\right.$ BIRTHS $\left._{i}\right)+\beta_{\mathrm{o}}+\beta_{1}$ RADIATION $_{i}$ for the analysis of the total data and

$$
\begin{gathered}
\log \left(\mu_{i a}\right)=\log \left(\text { BIRTHS }_{i a}\right)+\beta_{\mathrm{o}}+\beta_{1} \\
\text { RADIATION }_{i}+\text { AGEGP }_{a}
\end{gathered}
$$

for the data disaggregated by age group. Deviance differences from the models excluding ionising radiation were then examined to assess significance.

\section{Results}

The yearly prevalence rates of Down's syndrome by LMP are shown in figure 3. This prevalence reached a maximum in 1963-64, and two other maxima can be discerned in 1958 and 1986. The corresponding births of these babies showed a peak of 2.7 per 1000

\begin{tabular}{|c|c|c|c|c|c|c|c|c|}
\hline Model & $\begin{array}{l}\text { Base rate } \\
\text { (under 35) } \\
\hat{R}_{I}\end{array}$ & $\begin{array}{l}\text { Enhanced } \\
\text { rate (under } \\
\text { 35) } R_{2}\end{array}$ & $\begin{array}{l}\text { Base rate } \\
\text { ( } 35 \text { and } \\
\text { over) } \hat{R}_{3}\end{array}$ & $\begin{array}{l}\text { Enhanced } \\
\text { rate (35 } \\
\text { and over) } \\
\hat{R}_{4}\end{array}$ & $\begin{array}{l}\text { Start of } \\
\text { enhanced } \\
\text { period } \hat{j}\end{array}$ & $\begin{array}{l}\text { Length of } \\
\text { enhanced } \\
\text { period } \hat{k} \\
\text { (months) }\end{array}$ & $\begin{array}{l}\text { Change in } \\
\text { deviance }\end{array}$ & $p$ value \\
\hline \multicolumn{9}{|l|}{ All maternal ages: } \\
\hline & $0.0013^{*}$ & $0 \cdot 0054^{*}$ & - & - & Jun 58 & 6 & 13.08 & $0 \cdot 10$ \\
\hline Disaggregated by age group & $\begin{array}{l}0.0012^{*} \\
0.0007\end{array}$ & $\begin{array}{l}0.0031^{*} \\
0.0009\end{array}$ & $\overline{0} 0067$ & $-\overline{0131}$ & Oct 62 & 25 & $15 \cdot 35$ & 0.01 \\
\hline & 0.0007 & $\begin{array}{l}0 \cdot 0009 \\
0 \cdot 0014\end{array}$ & $\begin{array}{l}0.0067 \\
0.0064\end{array}$ & $\begin{array}{l}0.0431 \\
0.0153\end{array}$ & Aug 58 & $\begin{array}{r}4 \\
25\end{array}$ & $13 \cdot 74$ & $0 \cdot 10$ \\
\hline \multirow{2}{*}{$\begin{array}{l}\text { Specific maternal age groups: } \\
\text { Maternal age } 35 \text { and over only }\end{array}$} & & & & & & & $11 \cdot 81$ & 0.30 \\
\hline & - & - & 0.0067 & 0.0428 & Aug 58 & 4 & $13 \cdot 70$ & 0.05 \\
\hline \multirow{3}{*}{ Maternal age under 35 only } & $\overline{0.0007}$ & $\overline{0} 0_{013}$ & 0.0064 & 0.0186 & $\operatorname{Jan} 63$ & 18 & $10 \cdot 40$ & $0 \cdot 32$ \\
\hline & $0 \cdot 0007$ & 0.0043 & - & - & Dec 85 & 5 & $11 \cdot 09$ & $0 \cdot 19$ \\
\hline & $0 \cdot 0007$ & 0.0023 & - & - & Mar 64 & 11 & $6 \cdot 28$ & 0.56 \\
\hline
\end{tabular}
total births in 1959 and 3.3 in 1964, mostly due to the 35 years and over maternal age group in whom the prevalence increased more than twofold.

Table 1 Estimation of temporal peak models 


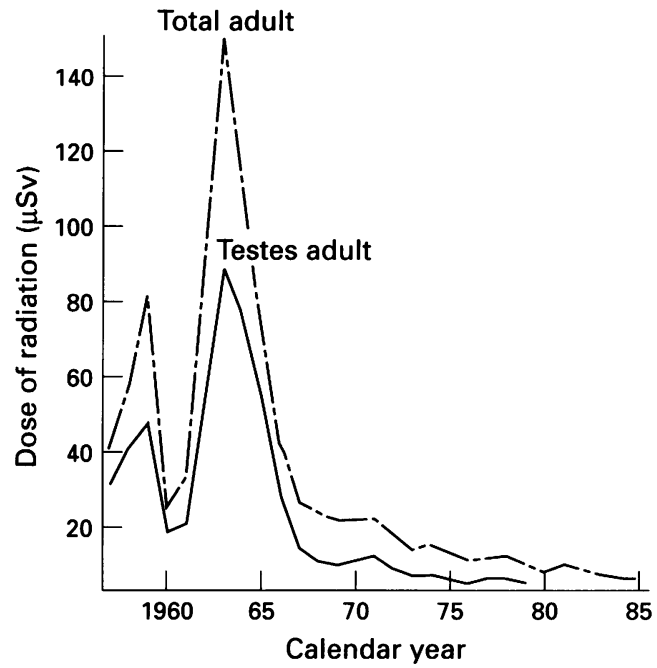

Figure 4 Estimated dose equivalents of radiation from weapons fallout.

Figure 2 shows that the proportion of mothers aged 35 years and over was not increasing in 1958 or in 1963-64. The proportion of mothers aged 40 years and over was not available in 1958, but in 1963 and 1964 it was 0.03 and was unchanged over the next four years.

Table 1 shows the estimates and deviance differences for the analyses of temporal peaks, both for the total cases, for the total data disaggregated by age group, and separately for the two age groups. In the analysis of the total data, the period of increased prevalence (in terms of LMP dates) is estimated to be a 25 month period from October 1962 until November 1964 . The simulation study shows that this is significant at the $1 \%$ level for the aggregated data, but fails to reach statistical significance when the data are disaggregated by age group, indicating that the two age groups behave somewhat differently. The disaggregated analysis shows the rate doubling for the under 35 age group in this 25 month period (from 7 in 10000 to 14 in 10000 cases) and more than doubling in the 35 and over age group (from 64 in 10000 to 153 in 10000 cases). For the 35 and over age group alone, an 18 month peak is detected from January 1963 until June 1964, whereas for the under 35 age group, a minor peak is detected slightly later, from March 1964 to January 1965.

The same alternative solution is also detected in all but one of the analyses, giving an estimate of a three to six month peak in the late summer and autumn of 1958. This peak has a sig- nificance level of $5 \%$ for the 35 and over age group, and a significance level of $10 \%$ for all cases. The disaggregated analysis shows the rate increasing more than sixfold for the 35 and over group (from 67 in 10000 to 431 in 10000 births), but barely increasing for the mothers aged under 35 years.

The 1986 peak in prevalence observed in figure 3 fails to reach statistical significance in any of the analyses but the early part of the year, mainly before the Chernobyl accident, is identified as a peak in the under 35 age group. Five of the nine cases in 1986 have LMP dates after the accident, with four of these in the 35 and over age group.

Further analyses were also carried out where a long term linear trend was also included in the model. In all analyses, the results were very similar to those obtained without a trend, with similar peaks and deviance differences, and in no case was the linear trend significant.

There was also no evidence of temporal dependence in the data, with an added autoregression term (logged or unlogged) with lag one month failing to reach statistical significance for both the aggregated and the disaggregated analysis ( $p>0 \cdot 25)$. In all cases, the peaks found were similar to those models without the autoregression terms.

Figure 4 shows the estimated dose equivalent from weapons fall out over the period of the study for the total adult dose and the dose to the testis. Both series show a strong peak in 1963 and 1964 and a smaller increase in the late 1950 s, peaking in 1959 .

Table 2 gives the results of fitting the log linear models, including each of the measures of radiation as an explanatory variable. The effect of total adult dose was found to be significant in both the aggregated $(p=0.002)$ and disaggregated $(p=0.03)$ analysis; that for the dose to the testis was also significant. In each case, after the explanatory variable was included, a goodness of fit test based on the scaled deviance showed a good fit to the Poisson distribution, with no evidence of over or underdispersion. Analyses with log transformed radiation variables also produced significant association, but these models fitted less well.

\section{Discussion}

Two pieces of evidence support our contention that ascertainment of Down's syndrome babies was as complete as is practical. Firstly, the

Table 2 Effect of radiation on the prevalence of Down's syndrome

\begin{tabular}{|c|c|c|c|c|c|}
\hline Model & $\hat{\beta}_{o}$ & $\hat{\beta}_{1}$ & Change in $d f$ & $\begin{array}{l}\text { Change in } \\
\text { deviance }\end{array}$ & $p$ value \\
\hline $\begin{array}{l}\text { Aggregated analysis: } \\
\text { Adult total dose equivalent }\end{array}$ & $-6 \cdot 843$ & $\begin{array}{l}0.0062 \\
0.00619\end{array}$ & 1 & $9 \cdot 18$ & 0.002 \\
\hline Adult dose to testis & $\begin{array}{c}(0.12) \\
-6.867 \\
(0.15)\end{array}$ & $\begin{array}{c}(0.0019) \\
0.010 \\
(0.0033)\end{array}$ & 1 & 8.97 & 0.003 \\
\hline \multicolumn{5}{|l|}{$\begin{array}{l}\text { Disaggregated by maternal age } \\
\text { group: }\end{array}$} & 0.03 \\
\hline Adult dose to testis & $\begin{array}{c}(0 \cdot 15) \\
-7 \cdot 39 \\
(0.17)\end{array}$ & $\begin{array}{c}(0.0020) \\
0.0082 \\
(0.0034)\end{array}$ & 1 & $5 \cdot 59$ & 0.02 \\
\hline
\end{tabular}

Note: standard errors are in parentheses. 
average prevalence in the Fylde over the 35 years was 1.35 per thousand births, which is in the range found by previous investigations. ${ }^{21}$ Secondly, the prevalence found in the first year (1989) of a national register of Down's syndrome ${ }^{22}$ was similar to that in the Fylde for the same year.

There was a significantly increased prevalence of Down's syndrome babies in 1963 and 1964 and a lesser peak in 1958, which did not quite reach statistical significance. Babies of mothers aged 35 years and over accounted for more of the variation, especially in 1958, when their increase was significant. Analysis of the total data disaggregated by age group showed that each age group behaved somewhat differently, which could account for the 1958 peak in all cases failing to reach statistical significance.

There was no evidence that the major peak in prevalence in 1963-64 was a result of changes in the maternal age distribution in the population. The proportion of mothers in the 35 years and over age group, within which the prevalence of Down's syndrome increases almost linearly with age, ${ }^{22}$ was not increasing. The possibility of a change in the detailed age distribution within the group, which might have some effect on prevalence, could not be ruled out completely because of a lack of available data, but seems unlikely as the proportion of mothers aged 40 years and over did not change from 1963-68.

We have shown that the "epidemic" of conceptions of Down's syndrome babies in 1963-64 coincided with the maximum estimated radiation dose from fall out from atmospheric testing of atomic weapons. We have also shown a highly significant association between the prevalence and radiation from fall out, which is independent of the significance or otherwise of the peaks. It should be noted that national figures for dose equivalents were used. Fallout deposition is approximately proportional to rainfall in the year ${ }^{23}$ and the actual doses in the Fylde were probably higher.

The minor peak in prevalence of Down's syndrome in 1958 was also associated with increased radiation exposure from fallout. That from atomic weapon testing was rising, although the peak occurred in the following year on that occasion. However, it is possible that radiation levels in the Fylde in 1958 were enhanced from radioactive ground deposits after the Windscale reactor fire in October 1957. There was evidence that the area was affected by the passage of the radioactive cloud. ${ }^{24}$ In 1986, exposure to radiation after the Chernobyl accident (26 April) was of a similar type to that received from weapons fallout, ${ }^{9}$ but the average effective dose equivalent was only about $25 \%$ of the average dose received in 1963 from fallout. ${ }^{25}$ Our findings were not impressive, but an increased prevalence of Down's syndrome after the accident was reported from the Lothian region of Scotland ${ }^{26}$ and West Berlin. ${ }^{27}$

Our findings on the possible effects of fallout are explicable if two tenets are accepted. Firstly, that very low doses of radiation may cause some cell damage. ${ }^{28}{ }^{29}$ Secondly, that the total dose of radiation received over the individual's lifetime determines the risk to health, ${ }^{30}$ the effects of radiation on tissues being cumulative. We suggest that in some mothers radiation effects on the ovary accumulated over many years can be enhanced by the comparatively low doses from fallout sufficiently to increase the risk of non-disjunction. The average dose to the ovaries from natural background radiation amounts to $35 \mathrm{mSv}$ by the age of 35 years. $^{6}$ Some studies of the effects of diagnostic medical radiation have suggested roughly $20 \mathrm{mSv}$ as a doubling dose for the risk of Down's syndrome, ${ }^{6}$ although the authors of one study state that the margin of error must be very great. ${ }^{5}$ Nevertheless, these figures indicate that our suggestion is not inherently improbable. We imply that the second meiotic division of the ovum will be affected. Among Down's syndrome cases of maternal origin non-disjunction occurs in some $20 \%$ at this division. ${ }^{31}$

Apart from fallout, the other two important man made sources of radiation to be considered were medical procedures and discharge from Sellafield. There was no suggestion of a sudden, temporary increase in exposure to medical radiation of the Fylde population in the early 1960s when considering the number of diagnostic $x$ ray examinations and the probable dose associated with them. The number of examinations at Victoria Hospital, Blackpool, where $80-90 \%$ of $x$ rays in the Fylde were taken, showed very little change between 1957 and 1962 after increasing by an average rate of $14.5 \%$ annually for the previous four years. In 1963 and 1964, the number increased again by an average of $14 \%$ each year, but then continued to increase until 1989 , although the rate showed a declining trend. With the publication of reports on the hazards of radiation by the Medical Research Council, ${ }^{32}$ in 1956 and the Adrian Committee ${ }^{33}$ in 1960 , the radiologist in charge at Victoria Hospital was already rigorously implementing the recommendations on reducing patient genetic dosage.

Data on liquid discharges from Sellafield did not show a peak in $1963-64^{34}$ but some 10 years later. Routine aerial discharges should not affect the Fylde, but if they did there was no peak in the early 1960s. Thus, there is no reason to connect Sellafield discharges with our "epidemic" of Down's syndrome babies.

Our study provides further support for radiation as one aetiological factor in Down's syndrome. Medical radiation and fallout seem to increase the chance of a mother having a Down's syndrome baby. All man made sources of exposure must be eliminated or kept to an essential minimum. The effect of natural background radiation accumulated over many years is probably another factor, but further detailed studies in different areas, especially some with higher levels of radiation, might help to confirm this. There seems to be little prospect of prevention of Down's syndrome in the near future. Reduction in numbers by improving antenatal diagnosis with a view to termination of the pregnancy must be actively pursued. 
We thank Dr K A Rowley, Consultant Radiologist, for information on $x$ ray practice in the Fylde during the first 28 years. We are grateful to Drs R Berry, K Binks, A Slovak and E J Tawn for helpful discussions and comments. We are also grateful to Professor J W Boag and Dr J Meredith for advice and encouragement.

1 United Nations Scientific Committee on the Effects of Atomic Radiation. Report. New York: United Nations, 1982:11-49.

2 Ujeno Y. Epidemiological studies on disturbances of human fetal development in areas with various doses of natural background radiation. 1. Relationship between incidences of Down's syndrome or visible malformation and gonad of Down's syndrome or visible malformation and gonad dose equivalent rate of natural back

3 Uchida IA, Holunga R, Lawler C. Maternal radiation and chromosomal aberrations. Lancet 1968;ii:1045-9.

4 Stevenson AC, Mason R, Edwards KD. Maternal diagnostic $\mathrm{x}$-irradiation before conception and the frequency of mongolism in children subsequently born. Lancet 1970;ii 1335-7.

5 Alberman E, Polani PE, Fraser Roberts JA, Spicer CC, Elliott M, Armstrong E. Parental exposure to $\mathrm{x}$-irradiation and Down's syndrome. Ann Hum Genet 1972;36:195-207.

6 Rose KSB. Epidemiological surveys of the effects of low-level radiation dose: a comparative assessment. Volume A: Preradiation dose: a comparative assessmelt. Volume A: Preconception irradiation effects. Harwell Laboratory, Ox1988:1-89.

7 Bound JP, Harvey PW, Francis BJ. Seasonal prevalence of major congenital malformations in the Fylde of Lancashir 1957-1981. F Epidemiol Community Health 1989;43:33042.

8 Dionian J, Wan SL, Wrixon AD. Radiation doses to member of the public around AWRE, Aldermaston, ROF, Burghfield and AERE, Harwell. London: HMSO, 1987:49 (NRPBR202).

9 Darby SC, Olsen JH, Doll R, et al. Trends in childhood leukaemia in the Nordic countries in relation to fallout from atmospheric nuclear weapons testing. BMF 1992; 304: 1005-9.

10 Hastie TJ, Tibshirani RJ. Generalized additive models. London: Chapman and Hall. 1990.

11 Green PJ, Yandell B. Semi-parametric generalized linear models. In: Gilchrist R, Francis BJ, Whittaker JC, eds. Proceedings of the 2 nd International GLIM conference, Lecture Notes in Statistics, Vol 32, New York: Springer Verlag, Notes in Statist

12 Francis BJ, Green M, Payne C, editors. The GLIM4 manual. Oxford: Oxford University Press. 1993

13 Stasinopoulos D, Francis BJ. Fitting GAMs in GLIM4. GLIM Newsletter 1993;22:30-6.

14 Tango $\mathrm{T}$. The detection of disease clustering in time. Biometrics $1984 ; 40: 15-26$.
15 Best DJ, Rayner JCW. Disease clustering in time. Biometrics 1991;47:589-93.

16 Ederer F, Myers M, Mantel N. A statistical problem in space and time: Do leukaemia cases come in clusters? Biometrics 1964;20:626-38.

17 Naus J. The distribution of the size of the maximum number of points on a line. Fournal of the American Statistical Association 1965;60:532-8.

$18 \mathrm{Knox}$ G. The detection of space-time interactions. Applied Statistics 1964;13:25-30.

19 Roberson P. Controlling for time-varying population distributions in disease clustering studies. Am $\mathcal{F}$ Epidemiol 1990;132:S131-5.

20 Lindsey, J. Analysis of repeated measurements. Oxford: Oxford University Press. 1993;54-6.

21 Hook EB, Porter IH. Human population cytogenetics: comments on racial differences in frequency of chromosome abnormalities, putative clustering of Down's syndrome, and radiation studies. In: Population cytogenetics. New York: Academic Press, 1976:353-65.

22 Mutton DE, Alberman E, Ide R, Bobrow M. Results of first year (1989) of a national register of Down's syndrome in England and Wales. BMF 1991;303:1295-7.

23 National Radiological Protection Board. The risks of leukaemia and other cancers in Seascale from radiation exposure. London: HMSO, 1984:68. (NRPB-R171).

24 Stewart NG, Crooks RN. Long-range travel of the radioactive cloud from the accident at Windscale. Nature 1958; 182:627-8.

25 Hughes JS, Shaw KB, O'Riordan MC. Radiation exposure of the UK population - 1988 review. London: HMSO, 1989: 15-8 (NRPB-R227).

26 Ramsay CN, Ellis PM, Zeally H. Down's syndrome in the Lothian region of Scotland - 1978 to 1989 . Biomed \& Pharmacother 1991;45:267-72.

27 Sperling K, Pelz J, Wegner RD, Schulzke I, Struck E. Frequency of trisomy 21 in Germany before and after the Chernobyl accident. Biomed Pharmacother 1991;45: 255-62.

28 Gillis NE. Effects of radiation on cells. BMF 1987;295: 1390-1.

29 Dunster HJ. The appreciation of radiation risks. $f R$ Coll Physicians Lond 1990;24:154-5.

30 Rose G. Environmental health: problems and prospects. $\mathcal{f}$ $R$ Coll Physicians Lond 1991;25:48-52.

31 International Commision for protection against environmental mutagens and carcinogens, ICPEMC meeting report no. 3. Is the incidence of Down's syndrome ing report no. 3. Is the incidence of

32 Medical Research Council. The hazards to man of nuclear and allied radiations. London: HMSO, 1956.

33 Ministry of Health. Department of Health for Scotland. Radiological hazards to patients. Second report of the committee. London: HMSO, 1960.

34 Black D. Investigation of the possible increased incidence of cancer in West Cumbria. Report of the Independent Advisory Group. London: HMSO, 1984:47-53. 